\title{
Mirabegron in the Treatment of Overactive Bladder: Safety and Efficacy in the Very Elderly Patient
}

This article was published in the following Dove Press journal:

Clinical Interventions in Aging

\author{
Asad Makhani (D) \\ Miriam Thake $\mathbb{D}^{2}$ \\ William Gibson (D) ${ }^{1}$ \\ 'University of Alberta, Division of \\ Geriatric Medicine, Edmonton, Alberta, \\ Canada; ${ }^{2}$ Great Western Hospitals NHS \\ Foundation Trust, Swindon SN3 6BB, UK
}

Correspondence: William Gibson University of Alberta, Division of Geriatric Medicine, I-198 Clinical Sciences Building, II 35083 Ave,

Edmonton, Alberta

Tel +I 7802481969

Email wgibson@ualberta.ca

\begin{abstract}
Lower urinary tract symptoms, including urgency, urgency incontinence, frequency, and nocturia, are highly prevalent in older adults and are associated with significant morbidity and impairment in quality of life. When conservative measures such as bladder training fail to improve symptoms, pharmacological management is recommended by national and international guidelines. Mirabegron, an agonist of the $\beta 3$ adrenergic receptor, demonstrates similar efficacy to the anticholinergic drugs without the risk of anticholinergic effects, but experience and evidence in the very elderly population are limited. This narrative review examines the current evidence base for mirabegron in very elderly adults.
\end{abstract}

Keywords: overactive bladder, mirabegron, elderly, ageing, anticholinergic, urinary incontinence

\section{Introduction}

Lower urinary tract symptoms (LUTS), including urgency, frequency, and urgency incontinence, are highly prevalent in the general population and increase in prevalence with increasing age, ${ }^{1-3}$ with frail older adults having a higher prevalence of urinary incontinence than any other group with the exception of those with spinal cord injury. ${ }^{4}$ The most common cause of urinary incontinence in older people is overactive bladder $(\mathrm{OAB}),{ }^{1}$ the clinically defined syndrome of urgency, with or without urgency incontinence, and usually with frequency and nocturia, in the absence of infection or other pathology. ${ }^{5} \mathrm{OAB}$ is a disorder of the storage phase of the bladder, with urgency, the sudden desire to void which is difficult to defer, ${ }^{6}$ being the cardinal symptom. The pathophysiology of urgency and of overactive bladder remains unclear, with the urothelium, ${ }^{7}$ detrusor, ${ }^{8}$ and brain ${ }^{9}$ all being implicated. In older adults, changes in both the lower urinary tract and the brain are associated with development of LUTS, ${ }^{10}$ and the changes in the brain associated with LUTS, such as the development of white matter hyperintensities ${ }^{11}$ mean that OAB cannot be considered merely a disorder of the bladder, but may be as much of a "brain disease". 9

National and international guidelines for the management of $\mathrm{OAB}$ stress the importance of conservative management of LUTS, including fluid intake normalisation, assessment and treatment of comorbidities, reduction of polypharmacy and the avoidance of agents associated with the development of LUTS, and bladder training ${ }^{12-14}$ prior to pharmacological therapy. The available evidence does suggest that older adults are more likely than younger people to need pharmacotherapy in addition to conservative management to achieve satisfactory symptom control, and 
to need higher doses of medication to achieve the same degree of improvement compared to younger people. ${ }^{15}$

$\mathrm{OAB}$ has significant impact on quality of life, ${ }^{16}$ and older people with $\mathrm{OAB}$ are at increased risk of falls, ${ }^{17}$ have greater rates of anxiety and depression ${ }^{18}$ and hospitalisation ${ }^{19}$ than those without OAB. In addition, it is well recognised that older people with urinary incontinence do not report LUTS, ${ }^{20,21}$ and active case finding and treatment of LUTS are recommended. ${ }^{4}$

\section{Pharmacological Management of OAB}

For many years, the only available pharmacological agents for the management of $\mathrm{OAB}$ were antimuscarinic drugs, starting with oxybutynin in the $1970 \mathrm{~s}^{22}$ Oxybutynin is a nonselective antagonist of the muscarinic receptor and has a high incidence of anticholinergic side effects including blurred vision, dry mouth, and constipation, ${ }^{23,24}$ and discontinuation rates are high. ${ }^{25}$ More M2 and M3 selective agents including solifenacin, ${ }^{26}$ darifenacin, ${ }^{27}$ and fesoterodine ${ }^{28}$ were developed in the 2000s, but rates of anticholinergic side effects remain high and discontinuation is common, with a systematic review of anticholinergic trials reporting discontinuation rates ranging from $4 \%$ to $31 \%$ and $5 \%$ to $20 \%$ in treatment and placebo groups, respectively, at 12 weeks. ${ }^{29}$ More recently, concerns regarding the cognitive safety of anticholinergic medications have emerged, ${ }^{30}$ and the use of immediate-release oxybutynin is not recommended in older adults. ${ }^{31}$ There are data from cross-sectional and longitudinal studies that exposure to anticholinergic medications in general is associated with cognitive decline, ${ }^{30,32,33}$ and reported cases of delirium felt to be induced by antimuscarinics for OAB including solifenacin ${ }^{34}$ and tolterodine. ${ }^{35}$ Immediate release oxybutynin has demonstrable negative effects on cognition, ${ }^{31}$ but fesoterodine use does not impact the MMSE score ${ }^{36}$ and solifenacin has no detectable effect on cognition, specifically attention, working memory, episodic memory, and speed of memory, in elderly people with mild cognitive impairment. ${ }^{37}$ Trospium, being a quaternary amine, does not cross the blood-brain barrier and has no proven cognitive side effects. ${ }^{38}$

\section{Mirabegron}

Concerns regarding the use of anticholinergic medication as a treatment for $\mathrm{OAB}$, and in particular in older people, lead to the investigation of adrenergic receptors in the bladder as a therapeutic target. $\beta 3$ adrenergic receptors account for $95 \%$ of the adrenergic receptor DNA in the human bladder, and activating these receptors induces relaxation of the detrusor muscle in the filling phase, thereby reducing urgency. ${ }^{39}$ Mirabegron, a potent and selective $\beta 3$ adrenergic receptor agonist, first became available for use in the early $2010 \mathrm{~s},{ }^{40}$ and is currently the only available $\beta 3$ agonist in most countries. A second agent, Vibegron, is undergoing Phase III trials ${ }^{41}$ and is approved for use in Japan. ${ }^{42}$ Initial Phase I and II trials of mirabegron demonstrated safety and dose ranging, ${ }^{43}$ and were followed by large-scale phase III trials with placebo and active control, usually tolterodine, both alone and in combination with an anticholinergic agent, commonly solifenacin.

\section{Mirabegron as Monotherapy}

Khullar et al compared 1978 adults with OAB in a 1:1:1:1 ratio comparing placebo, mirabegron $50 \mathrm{mg}$, mirabegron $100 \mathrm{mg}$, and tolterodine ER $4 \mathrm{mg}$, recruiting from both Asia and Europe to the SCORPIO trial. ${ }^{44}$ Although included as an active control arm, statistical comparisons with tolterodine were not included in the analysis. Mirabegron leads to a reduction in the number of incontinence episodes per day $(-1.57$ and -1.46 for $50 \mathrm{mg}$ and $100 \mathrm{mg}$, respectively) compared to placebo and in number of voids per day, with 1.93 fewer with 50mg and 1.99 fewer with $100 \mathrm{mg}$ mirabegron. The reduction in the placebo group was 1.34. The mean age of participants in this trial was 59 (SD 12.3) years, and 173 participants were aged 75 or over, and the trial duration was relatively short at 12 weeks of active treatment.

In the ARIES trial in a North American population, Nitti and colleagues performed a pooled analysis of three trials comparing mirabegron $100 \mathrm{mg}, 50 \mathrm{mg}$, and placebo in a $1: 1: 1$ ratio, finding improvements in incontinence episodes per 24$\mathrm{h}$ period, reducing from baseline by 1.47 and 1.63 with mirabegron 50mg and $100 \mathrm{mg}$, respectively. ${ }^{45}$ Again, the participants in these trials were largely young, with a mean age of 59 years, and although the range of ages was reported (19-95), the proportion of participants aged $>75$ was not given.

Finally, Herschorn et al compared mirabegron $25 \mathrm{mg}$ and $50 \mathrm{mg}$ to placebo in a 12 -week randomized control trial. ${ }^{46}$ They found greater reductions in incontinence episodes with mirabegron $25 \mathrm{mg}$ and 50 compared to placebo (1.36 and 1.38 fewer episodes per $24 \mathrm{~h}$ respectively). In this group, $37 \%$ of participants were aged 65 or older, and 
only $9.6 \%$ (125) were aged 75 or older, and age-based subgroup analysis was not reported.

A systematic review of trials of mirabegron was conducted by Cui in $2014,{ }^{47}$ including four RCTs with a total of 5791 participants. They report that mirabegron was effective in treating $\mathrm{OAB}$ with a greater reduction in incontinence episodes of 0.44 episodes/day for mirabegron vs placebo, as well as reduced micturitions per day and episodes of urgency. They also analysed TEAEs, including included hypertension, arrhythmia, and urinary retention finding similar rates of discontinuation for TEAEs in the active and placebo groups, with pooled odds ratio of 1.22 (95\% CI 0.84-1.76). Cui did not report the age range or mean of the participants in the included trials.

To assess the efficacy and tolerability in older adults, Wagg and colleagues performed a prospective subgroup analysis of three 12-week efficacy trials and from a single one-year tolerability trial examining the effects in the over $65 \mathrm{~s}$ and over $75 \mathrm{~s} .{ }^{48}$ They found no significant differences in tolerability between the age groups over 1 year of follow up, with $49 \%$ of those in the pooled placebo group and $55 \%$ of those receiving $25 \mathrm{mg}$ of mirabegron experiencing a TEAE, compared to $49 \%$ in the tolterodine arms. The most common TEAEs in the over $65 \mathrm{~s}$ receiving mirabegron were hypertension $(9.9 \%)$, nasopharyngitis $(4.1 \%)$ and urinary tract infection $(3.1 \%)$. There was no difference in the efficacy between older and younger adults at 12 or 52 weeks.

\section{Mirabegron as Monotherapy in Older Adults}

Looking specifically at older people, the PILLAR study was a Phase 4, double-blind, parallel-group study of adults aged 65 and over. ${ }^{49}$ Wagg and colleagues recruited 888 adults aged 65 and over, randomising them to placebo $(n=443)$ or mirabegron $(n=445) 25 \mathrm{mg}$ or $50 \mathrm{mg}$, with an option to increase the dose at 4 and 8 weeks. Of those who received mirabegron, 226 received $25 \mathrm{mg}$ and 219 elected to titrate to mirabegron $50 \mathrm{mg}$ by the end of the study. Mirabegron was associated with a reduction in incontinence episodes from baseline of 2.06 episodes per $24 \mathrm{~h}$, compared to 1.57 for placebo, a greater increase in mean voided volume compared to placebo $(32.44 \mathrm{~mL}$ vs $18.49 \mathrm{~mL}$, respectively), and an improvement in quality of life, measured with the OAB-q symptom bother questionnaire, with reductions in the bother score of 18.7 in the placebo arm and 23.4 in the mirabegron arm of the trial.
Rates of treatment-emergent adverse events (TEAEs) were similar in all groups, with the most common TEAEs being headache $(5.2 \%$ mirabegron, $2.7 \%$ placebo). There were no significant differences in the rates of UTI, headache, or GI disturbance between the $<75$ and $\geq 75$ year groups. Cognitive safety was also assessed, with no statistically significant change in Montreal Cognitive Assessment score over the timescale of the study; patients on placebo experienced a mean change of 0.2 points vs -0.1 and 0.3 points for patients on mirabegron $25 \mathrm{mg}$ and $50 \mathrm{mg}$, respectively. The majority of the participants were female (72\%) and had severe symptoms, with the majority having OAB-wet. In addition, the authors did not assess frailty, potentially limiting the generalisability to more frail older adults.

\section{Mirabegron in Combination with Other Agents}

Mirabegron has also been tested in combination with other agents, typically solifenacin. In a Phase 2 double-blind RCT, the SYMPHONY trial, 1306 people with OAB were randomised to 12 groups; 6 of which were combination therapy (mirabegron 25 or $50 \mathrm{mg}$ with solifenacin 2.5 , 5 , or $10 \mathrm{mg}$ ), 5 monotherapy groups (mirabegron 25 or $50 \mathrm{mg}$ and solifenacin $2.5,5$, or $10 \mathrm{mg}$ ), or placebo. ${ }^{50} \mathrm{At}$ 12 weeks those treated with mirabegron $25 \mathrm{mg}$ or $50 \mathrm{mg}$ in combination with solifenacin $2.5 \mathrm{mg}, 5 \mathrm{mg}$, and $10 \mathrm{mg}$ had significant reduction in the primary endpoint, number of micturitions per $24 \mathrm{~h}$. There was a trend for increasing effect with increasing doses of solifenacin and mirabegron. All treatment groups, including placebo, demonstrated a reduction in the number of urgency episodes from baseline, and none of the active treatment groups significantly reduced incontinence episodes compared with placebo. No dose-related trends in TEAEs, specifically blood pressure, pulse rate, post-void residual volume, or laboratory or ECG parameters were observed between combination and monotherapy groups. There was a slight increase in constipation in the combination therapy group compared to the monotherapy and placebo arms. The mean age of participants was 54.8 years.

The use of mirabegron in combination with solifenacin was also assessed in the SYNERGY study. ${ }^{51}$ Adults with OAB-wet were, after a 4-week placebo run-in, randomized to solifenacin $5 \mathrm{mg}+$ mirabegron $25 \mathrm{mg}$ (combined S5 + M25 group); solifenacin $5 \mathrm{mg}+$ mirabegron $50 \mathrm{mg}$ (combined S5 + M50 group); solifenacin $5 \mathrm{mg}$; mirabegron $25 \mathrm{mg}$; mirabegron 
$50 \mathrm{mg}$; or placebo in a 2:2:1:1:1:1 ratio. Changes from baseline to end of treatment were reported at 12 weeks. The combination of solifenacin $5 \mathrm{mg}$ and mirabegron $50 \mathrm{mg}$ was superior to solifenacin $5 \mathrm{mg}$ in terms of incontinence reduction, with a mean-adjusted difference of -0.2 UI episodes per day, there was no observed difference between the combination and mirabegron 50mg monotherapy. Responder analyses demonstrated the superiority of both combined therapies vs monotherapies with respect to the proportion of patients with zero UI episodes and those achieving a normal micturition frequency. There was a slightly increased frequency of TEAEs in the combined therapy groups vs monotherapies and placebo, with $40.4 \%$ of those receiving solifenacin $5 \mathrm{mg}$ and mirabegron $25 \mathrm{mg}$, and $37 \%$ of those receiving solifenacin $5 \mathrm{mg}$ and mirabegron 50mg reporting a TEAE, compared to $33.8 \%$ in the placebo arm. Most of the TEAEs were mild or moderate in severity. The rates of typical anticholinergic effects were higher in those receiving solifenacin than not, but were not significantly higher in the combination groups than the solifenacin monotherapy arms. Of the 3398 participants, approximately three quarters were female, one third aged over 65 , and $8 \%$ over 75 . The mean age was 57 .

The BESIDE trial ${ }^{52}$ compared combination treatment with solifenacin and mirabegron over 12 weeks in adults who remained incontinent, defined as at least one episode of incontinence on a 3-day bladder diary, after a 4-week run-in period of solifenacin $5 \mathrm{mg}$. A total of 2174 patients were randomised to solifenacin $5 \mathrm{mg}$, solifenacin $10 \mathrm{mg}$, or solifenacin $5 \mathrm{mg}$ with mirabegron $25 \mathrm{mg}$ increasing to $50 \mathrm{mg}$ after 4 weeks. The primary end point, change from baseline to end of treatment micturitions per $24 \mathrm{~h}$, demonstrated greater efficacy (1.8 fever voids per $24 \mathrm{~h}$ ) with combination therapy than with solifenacin $5 \mathrm{mg}(1.53$ fewer voids per $24 \mathrm{~h}$ ), and the combination was noninferior to solifenacin $10 \mathrm{mg}$ for secondary end-points including incontinence episodes. Combination therapy was relatively well tolerated, with lower rates of TEAEs than solifenacin $10 \mathrm{mg}$ at $35.9 \%$ and $39.4 \%$, respectively, and discontinuation rates were low at $1.5 \%$ in all groups.

A pre-specified subgroup analysis of BESIDE by age was performed..$^{53} 30.9 \%$ of those in BESIDE were aged 65 and over, and $8.9 \%$ age 75 and over. When analysed as a full analysis set (FAS) using age as a stratifying variable, there were no significant differences between the age groups in terms of outcome measures, including incontinence episodes, urgency episodes, and voids per $24 \mathrm{~h}$. The over 75 group had slightly higher rates of constipation in all three treatment arms, and the rates of TEAEs of particular concern in older patients (hypertension, tachycardia, palpitations, QT prolongation, UTIs, and falls), were low $(<2 \%)$, irrespective of treatment or age. Cognition was not specifically tested in this trial, and all the participants were all community-dwelling.

Chapple and colleagues performed a pooled analysis of 10 phase 2 to 4 , double bind, 12 weeks studies of mirabegron, comparing those $<65 \mathrm{vs} \geq 65$ and $<75 \mathrm{vs} \geq 75 .{ }^{54}$ In total 11,261 patients were included, with a mean age of 575 years, $33-35 \%$ of patients in the full analysis set were aged 65 years or over, and $7-10 \%$ being 75 or over. The older patients were more likely to have hypertension or diabetes. Older adults in this analysis had a higher urinary frequency and more urgency. Men had greater frequency of nocturia at baseline than women (2.55 vs 1.99 , respectively), as well as a greater number of micturitions per 24 h (11.76 vs 11.47). The oldest group, those aged 75 and over, had higher mean episodes of incontinence per $24 \mathrm{~h}$ ( 2.93 vs 2.58 ), and nocturia episodes ( 2.55 vs 1.99 ). The overall frequency of TEAEs was around $5-10 \%$ higher in the oldest group compared to the youngest, with the effect off age more marked in those receiving antimuscarinics than those given mirabegron. Mirabegron $25 \mathrm{mg}$ and $50 \mathrm{mg}$, solifenacin $5 \mathrm{mg}$, and tolterodine $4 \mathrm{mg}$ were all associated with greater improvement from baseline than placebo, with the numerical change from baseline to end of treatment in incontinence episodes higher in the oldest group.

Finally, the SYNERGY II trial compared mirabegron and solifenacin in combination with each agent separately, with participants being randomised to mirabegron $50 \mathrm{mg}$, combination of mirabegron $50 \mathrm{mg}$ and solifenacin $5 \mathrm{mg}$, or solifenacin $5 \mathrm{mg}$ alone in a 1:4:1 ratio following a 2-week placebo run in period. ${ }^{55}$ Follow up was for 12 months, and the median age of participants was 61 (range 19-86). The majority of participants $(80 \%)$ were female and $34 \%$ were aged over $65.47 \%$ of participants experienced at least one TEAE, with $49 \%$ in the combination group, $44 \%$ in solifenacin, and $41 \%$ in the mirabegron group. The majority where mild (24\%), with $19 \%$ being moderate and $4 \%$ severe. The rate of anticholinergic effects were higher in the solifenacin and combination groups than mirabegron with dry mouth in $6.1 \%$ in the combination arm, 5.9\% with solifenacin and $3.9 \%$ with mirabegron. There were no differences in discontinuation rates. The primary endpoint, change in incontinence episodes per 24 hours from baseline, was -2.0 in the combination group, -1.9 with solifenacin, and -1.6 with 
mirabegron $(\mathrm{p}<0.001)$, suggesting that combination therapy was superior to monotherapy with either mirabegron or solifenacin without increased risk of adverse events. A subgroup analysis of the older participants was not reported, and it is noteworthy that the most of the participants in SYNERGY II had completed SYNERGY or BESIDE, and may therefore had been preselected as responding to therapy through recruitment bias.

\section{Pharmacological Management of Incontinence in the Frail}

None of the published studies of mirabegron have focussed on frail older adults. The fifth International Consultation in Incontinence notes that:

frail people with UI should be considered for drug treatment only following a comprehensive evaluation of remediable causative factors, and an evaluation for and trial of appropriate behavioural therapy and lifestyle interventions. Drug treatment should not generally be used for people who make no attempt to toilet when aided, become agitated with toileting, or are so functionally and cognitively impaired that there is no prospect of meaningful benefit, ${ }^{4}$

And that frailty, not age, should drive treatment decisions. In older adults, Oelke and colleagues used a DELPHI method to apply the FORTA (Fit fOR the Aged) classification to the available pharmacological agents for OAB. ${ }^{56}$ Only fesoterodine was granted a FORTA-B (beneficial) classification, and mirabegron, along with solifenacin, darifenacin, extended-release oxybutynin, tolterodine, and trospium were assigned FORTA-C (questionable, use with caution). FORTA-D (avoid) was assigned to immediate release oxybutynin and propiverine.

A multicriterion decision analysis has been contrasted using the available efficacy and safety data from published randomized and placebo-controlled trials of mirabegron, antimuscarinic agents, and the combination. ${ }^{57}$ Sixty references were identified and included, covering 14 common drugs, and an expert panel including urologists, urogynaecologists, and geriatricians constructed and validated the model. The conclusions drawn were that flexible-dose fesoterodine (4mg or $8 \mathrm{mg}$ ) provided the highest efficacy, and mirabegron $25 \mathrm{mg}$ the highest tolerability, with the combination of mirabegron $25 \mathrm{mg}$ and solifenacin $5 \mathrm{mg}$ being the closest to the ideal treatment option of perfect efficacy with no side effects.

\section{Conclusion}

$\mathrm{OAB}$ is common, under-reported and distressing for older adults. The available data suggest that mirabegron is as efficacious as the other available pharmacological agents, with lower rates of bothersome anticholinergic side effects and similar overall TEAE rates. The data suggest that, overall, mirabegron and the newer anticholinergic agents for $\mathrm{OAB}$ are similar in safety and efficacy, with fesoterodine having the best FORTA rating of the available drugs. As with all agents, the data specifically in the very elderly and frail are sparse, but those which are available do support the addition of mirabegron to the armamentarium of treatments for OAB when monotherapy has failed. For those at higher risk of anticholinergic effects, such as preexisting cognitive impairment, neurological disease, and polypharmacy, mirabegron provides a valuable treatment option.

\section{Disclosure}

Dr William Gibson reports grants, personal fees from Pfizer and Astellas, during the conduct of the study. The authors report no other conflicts of interest in this work.

\section{References}

1. Irwin DE, Milsom I, Hunskaar S, et al. Population-based survey of urinary incontinence, overactive bladder, and other lower urinary tract symptoms in five countries: results of the EPIC study. Eur Urol. 2006;50(6):1306-14; discussion 1314-5. doi:10.1016/j.eururo. 2006.09.019

2. Donaldson MM, Thompson JR, Matthews RJ, et al. The natural history of overactive bladder and stress urinary incontinence in older women in the community: a 3-year prospective cohort study. Neurourol Urodyn. 2006;25(7):709-716. doi:10.1002/nau.20235

3. Milsom I, Abrams P, Cardozo L, et al. How widespread are the symptoms of an overactive bladder and how are they managed? A population-based prevalence study. BJU Int. 2001;87(9):760-766. doi:10.1046/j.1464-410x.2001.02228.x

4. Wagg A, Gibson W, Ostaszkiewicz J, et al. Urinary incontinence in frail elderly persons: report from the 5th International Consultation on Incontinence. Neurourol Urodyn. 2015;34(5):398-406. doi:10. 1002/nau.22602

5. Abrams P, Artibani W, Cardozo L, et al. Reviewing the ICS 2002 terminology report: the ongoing debate. Neurourol Urodyn. 2009;28 (4):287. doi:10.1002/nau.20737

6. Abrams P, Cardozo L, Fall M, et al. The standardisation of terminology of lower urinary tract function: report from the Standardisation Sub-committee of the International Continence Society. Neurourol Urodyn. 2002;21(2):167-178. doi:10.1002/nau.10052

7. de Groat WC. The urothelium in overactive bladder: passive bystander or active participant? Urology. 2004;64(6 Suppl 1):7-11. doi:10.1016/ j.urology.2004.08.063

8. Brading AF. A myogenic basis for the overactive bladder. Urology. 1997;50(6A Suppl):57-67; discussion 68-73. doi:10.1016/S00904295(97)00591-8 
9. Sakakibara R, Panicker J, Fowler CJ, et al. Is overactive bladder a brain disease? The pathophysiological role of cerebral white matter in the elderly. Int J Urol. 2014;21(1):33-38. doi:10.1111/iju.12288

10. Gibson W, Wagg A. Incontinence in the elderly, 'normal' ageing, or unaddressed pathology? Nat Rev Urol. 2017;14(7):440-448. doi:10.1038/nrurol.2017.53

11. Gary B, Perera S, Murrin A, Aizenstein H, Tadic S. White matter hyperintensity burden and depression are associated with severity and impact of urgency urinary incontinence in functional, community-dwelling older women. Neurourol Urodyn. 2013;32(6):798-799.

12. NICE UK. Urinary Incontinence: The Management of Urinary Incontinence in Women (CG40); 2006.

13. UK NICE. GC 97: the management of lower urinary tract symptoms in men; 2010. Available from: http://www.nice.org.uk/CG97. Accessed March 27, 2020.

14. Corcos J, Przydacz M, Campeau L, et al. CUA guideline on adult overactive bladder. Can Urol Assoc J. 2017;11(5):E142-E173. doi:10.5489/cuaj. 4586

15. Wagg A. Treating overactive bladder in the elderly. Can Urol Assoc J. 2011;5(5 Suppl 2):S149-51. doi:10.5489/cuaj.11188

16. Wagner TH, Hu TW, Bentkover J, et al. Health-related consequences of overactive bladder. Am J Manag Care. 2002;8(19 Suppl):S598-607.

17. Gibson W, Hunter KF, Camicioli R, et al. The association between lower urinary tract symptoms and falls: forming a theoretical model for a research agenda. Neurourol Urodyn. 2018;37(1):501-509. doi:10.1002/nau.23295

18. Coyne KS, Sexton CC, Irwin DE, et al. The impact of overactive bladder, incontinence and other lower urinary tract symptoms on quality of life, work productivity, sexuality and emotional well-being in men and women: results from the EPIC study. BJU Int. 2008;101 (11):1388-1395. doi:10.1111/j.1464-410X.2008.07601.x

19. Thom DH, Haan MN, Van Den Eeden SK. Medically recognized urinary incontinence and risks of hospitalization, nursing home admission and mortality. Age Ageing. 1997;26(5):367-374. doi:10.1093/ageing/26.5.367

20. Teunissen D, van Weel C, Lagro-Janssen T. Urinary incontinence in older people living in the community: examining help-seeking behaviour. Br J Gen Pract. 2005;55(519):776-782.

21. Shaw C, Tansey R, Jackson C, Hyde C, Allan R. Barriers to help seeking in people with urinary symptoms. Fam Pract. 2001;18 (1):48-52. doi:10.1093/fampra/18.1.48

22. Thompson IM, Lauvetz R. Oxybutynin in bladder spasm, neurogenic bladder, and enuresis. Urology. 1976;8(5):452-454. doi:10.1016/ 0090-4295(76)90273-9

23. Riva D, Casolati E. Oxybutynin chloride in the treatment of female idiopathic bladder instability. Results from double blind treatment. Clin Exp Obstet Gynecol. 1984;11(1-2):37-42.

24. Thuroff JW, Bunke B, Ebner A, et al. Randomized, double-blind, multicenter trial on treatment of frequency, urgency and incontinence related to detrusor hyperactivity: oxybutynin versus propantheline versus placebo. J Urol. 1991;145(4):813-6; discussion 816-7. doi:10.1016/S0022-5347(17)38459-8

25. Yoo DS, Han JY, Lee KS, Choo MS. Prescription pattern of oxybutynin ER in patients with overactive bladder in real life practice: a multicentre, open-label, prospective observational study. Int J Clin Pract. 2012;66(2):132-138. doi:10.1111/j.1742-1241.2011.02838.x

26. Chapple CR, Rechberger T, Al-Shukri S, et al. Randomized, double-blind placebo- and tolterodine-controlled trial of the once-daily antimuscarinic agent solifenacin in patients with symptomatic overactive bladder. BJU Int. 2004;93(3):303-310. doi:10.1111/ j.1464-410X.2004.04606.X

27. Chapple C, Steers W, Norton P, et al. A pooled analysis of three phase III studies to investigate the efficacy, tolerability and safety of darifenacin, a muscarinic M3 selective receptor antagonist, in the treatment of overactive bladder. BJU Int. 2005;95(7):993-1001. doi:10.1111/j.1464-410X.2005.05454.x
28. Chapple C, Van Kerrebroeck P, Tubaro A, et al. Clinical efficacy, safety, and tolerability of once-daily fesoterodine in subjects with overactive bladder. Eur Urol. 2007;52(4):1204-1212. doi:10.1016/j. eururo.2007.07.009

29. Sexton CC, Notte SM, Maroulis C, et al. Persistence and adherence in the treatment of overactive bladder syndrome with anticholinergic therapy: a systematic review of the literature. Int $J$ Clin Pract. 2011;65(5):567-585. doi:10.1111/j.1742-1241.2010.02626.x

30. Boustani M, Campbell N, Munger S, Maidment I, Fox C. Impact of anticholinergics on the aging brain: a review and practical application. Aging Health. 2008;4(3):311-320. doi:10.2217/ 1745509X.4.3.311

31. Gibson W, Athanasopoulos A, Goldman H, et al. Are we shortchanging frail older people when it comes to the pharmacological treatment of urgency urinary incontinence? Int J Clin Pract. 2014;68 (9):1165-1173. doi:10.1111/ijcp.12447

32. Bottiggi KA, Salazar JC, Yu L, et al. Long-term cognitive impact of anticholinergic medications in older adults. Am J Geriatr Psychiatry. 2006;14(11):980-984. doi:10.1097/01.JGP.0000224619.87681.71

33. Campbell N, Boustani M, Limbil T, et al. The cognitive impact of anticholinergics: a clinical review. Clin Interv Aging. 2009;4:225-233. doi:10.2147/cia.s5358

34. Stuhec M. Solifenacin-induced delirium and hallucinations. Gen Hosp Psychiatry. 2013;35(6):682 e3-4. doi:10.1016/j.genhosppsych.2013.06.002

35. Tsao JW, Heilman KM. Transient memory impairment and hallucinations associated with tolterodine use. $N$ Engl J Med. 2003;349 (23):2274-2275. doi:10.1056/NEJM200312043492325

36. Wagg A, Khullar V, Michel MC, et al. Long-term safety, tolerability and efficacy of flexible-dose fesoterodine in elderly patients with overactive bladder: open-label extension of the SOFIA trial. Neurourol Urodyn. 2014;33(1):106-114.

37. Wagg A, Dale M, Tretter R, Stow B, Compion G. Randomised, multicentre, placebo-controlled, double-blind crossover study investigating the effect of solifenacin and oxybutynin in elderly people with mild cognitive impairment: the SENIOR study. Eur Urol. 2013;64(1):74-81. doi:10.1016/j.eururo.2013.01.002

38. Staskin D, Kay G, Tannenbaum C, et al. Trospium chloride has no effect on memory testing and is assay undetectable in the central nervous system of older patients with overactive bladder. Int $J$ Clin Pract. 2010;64(9):1294-1300. doi:10.1111/j.1742-1241.2010.02433.x

39. Michel MC. $\beta$-Adrenergic receptor subtypes in the urinary tract. Handb Exp Pharmacol. 2011;202:307-318.

40. Bhide AA, Digesu GA, Fernando R, Khullar V. Mirabegron - a selective beta3-adrenoreceptor agonist for the treatment of overactive bladder. Res Rep Urol. 2012;4:41-45. doi:10.2147/RRU.S28930

41. Yoshida M, Takeda M, Gotoh M, Nagai S, Kurose T. Vibegron, a novel potent and selective beta3-adrenoreceptor agonist, for the treatment of patients with overactive bladder: a randomized, double-blind, Placebo-controlled Phase 3 Study. Eur Urol. 2018;73 (5):783-790. doi:10.1016/j.eururo.2017.12.022

42. Keam SJ. Vibegron: first global approval. Drugs. 2018;78 (17):1835-1839. doi:10.1007/s40265-018-1006-3

43. Sacco E, Bientinesi R, Tienforti D, et al. Discovery history and clinical development of mirabegron for the treatment of overactive bladder and urinary incontinence. Expert Opin Drug Discov. 2014;9 (4):433-448. doi:10.1517/17460441.2014.892923

44. Khullar V, Amarenco G, Angulo JC, et al. Efficacy and tolerability of mirabegron, a beta(3)-adrenoceptor agonist, in patients with overactive bladder: results from a randomised European-Australian phase 3 trial. Eur Urol. 2013;63(2):283-295. doi:10.1016/j. eururo.2012.10.016

45. Nitti VW, Khullar V, van Kerrebroeck P, et al. Mirabegron for the treatment of overactive bladder: a prespecified pooled efficacy analysis and pooled safety analysis of three randomised, double-blind, placebo-controlled, phase III studies. Int J Clin Pract. 2013;67 (7):619-632. doi:10.1111/ijcp.12194 
46. Herschorn S, Barkin J, Castro-Diaz D, et al. A Phase III, randomized, double-blind, parallel-group, placebo-controlled, multicentre study to assess the efficacy and safety of the beta(3) adrenoceptor agonist, mirabegron, in patients with symptoms of overactive bladder. Urology. 2013;82(2):313-320. doi:10.1016/j. urology.2013.02.077

47. Cui Y, Zong H, Yang C, Yan H, Zhang Y. The efficacy and safety of mirabegron in treating OAB: a systematic review and meta-analysis of phase III trials. Int Urol Nephrol. 2014;46(1):275-284. doi:10.1007/s11255-013-0509-9

48. Wagg A, Cardozo L, Nitti VW, et al. The efficacy and tolerability of the beta3-adrenoceptor agonist mirabegron for the treatment of symptoms of overactive bladder in older patients. Age Ageing. 2014;43 (5):666-675. doi:10.1093/ageing/afu017

49. Wagg A, Staskin D, Engel E, et al. Efficacy, safety, and tolerability of mirabegron in patients aged $\geq 65$ years with overactive bladder wet: a Phase IV, double-blind, randomised, placebo-controlled study (PILLAR). Eur Urol. 77(2):211-220.

50. Abrams P, Kelleher C, Staskin D, et al. Combination treatment with mirabegron and solifenacin in patients with overactive bladder: efficacy and safety results from a randomised, double-blind, dose-ranging, phase 2 study (Symphony). Eur Urol. 2015;67 (3):577-588. doi:10.1016/j.eururo.2014.02.012

51. Herschorn S, Chapple CR, Abrams P, et al. Efficacy and safety of combinations of mirabegron and solifenacin compared with monotherapy and placebo in patients with overactive bladder (SYNERGY study). BJU Int. 2017;120(4):562-575. doi:10.1111/bju.13882
52. Drake MJ, Chapple C, Esen AA, et al. Efficacy and safety of mirabegron add-on therapy to solifenacin in incontinent overactive bladder patients with an inadequate response to initial 4-week solifenacin monotherapy: a randomised double-blind multicentre Phase 3B Study (BESIDE). Eur Urol. 2016;70(1):136-145. doi:10.1016/j.eururo.2016.02.030

53. Gibson W, MacDiarmid S, Huang M, et al. Treating overactive bladder in older patients with a combination of mirabegron and solifenacin: a prespecified analysis from the BESIDE Study. Eur Urol Focus. 2017;3(6):629-638. doi:10.1016/j.euf.2017.08.008

54. Chapple CR, Cruz F, Cardozo L, et al. Safety and efficacy of mirabegron: analysis of a large integrated clinical trial database of patients with overactive bladder receiving mirabegron, antimuscarinics, or Placebo. Eur Urol. 77(1):119-128.

55. Gratzke C, van Maanen R, Chapple C, et al. Long-term safety and efficacy of mirabegron and solifenacin in combination compared with monotherapy in patients with overactive bladder: a randomised, multicentre Phase 3 Study (SYNERGY II). Eur Urol. 2018;74 (4):501-509. doi:10.1016/j.eururo.2018.05.005

56. Oelke M, Becher K, Castro-Diaz D, et al. Appropriateness of oral drugs for long-term treatment of lower urinary tract symptoms in older persons: results of a systematic literature review and international consensus validation process (LUTS-FORTA 2014). Age Ageing. 2015;44(5):745-755. doi:10.1093/ageing/afv077

57. Chapple CR, Mironska E, Wagg A, et al. Multicriteria decision analysis applied to the clinical use of pharmacotherapy for overactive bladder symptom complex. Eur Urol Focus. 2019. doi:10.1016/j. euf.2019.09.020
Clinical Interventions in Aging

\section{Publish your work in this journal}

Clinical Interventions in Aging is an international, peer-reviewed journal focusing on evidence-based reports on the value or lack thereof of treatments intended to prevent or delay the onset of maladaptive correlates of aging in human beings. This journal is indexed on PubMed Central, MedLine, CAS, Scopus and the Elsevier

\section{Dovepress}

Bibliographic databases. The manuscript management system is completely online and includes a very quick and fair peer-review system, which is all easy to use. Visit http://www.dovepress.com/ testimonials.php to read real quotes from published authors. 